\title{
A Patient with Fatal Necrotizing Fasciitis following the Use of Intra-Articular Sodium Hyaluronate Injections: A Case Report
}

\author{
Shanti Virupannavar ${ }^{1}$ and Carla Guggenheim ${ }^{2}$ \\ ${ }^{1}$ Internal Medicine, Michigan State University, 138 Service Road, A225 Clinical Center, East Lansing, MI 48824, USA \\ ${ }^{2}$ Internal Medicine and Rheumatology, Michigan State University, 138 Service Road, A225 Clinical Center, \\ East Lansing, MI 48824, USA
}

Correspondence should be addressed to Shanti Virupannavar; shantivirup@gmail.com

Received 23 September 2013; Accepted 7 December 2013

Academic Editor: Jeffrey M. Weinberg

Copyright (C) 2013 S. Virupannavar and C. Guggenheim. This is an open access article distributed under the Creative Commons Attribution License, which permits unrestricted use, distribution, and reproduction in any medium, provided the original work is properly cited.

\begin{abstract}
Introduction. Osteoarthritis, a degenerative joint disease, is a key cause of disability around the world and an ever-growing public health concern. Intra-articular hyaluronic acid viscosupplementation is used as a conservative option for osteoarthritis knee pain relief (McArthur et al., 2012; Hootman and Helmick, 2006; Huang el al., 2011). In general, the literature has shown an excellent safety profile for this treatment modality (McArthur et al., 2012; Clegg et al., 2013; Hammesfahr et al., 2003; Neustadt et al., 2005; Cohen et al., 2008; Neustadt, 2003; Jüni et al., 2007; Peterson and Hodler, 2011). Case Presentation. In this report, we describe a case of a woman who had received multiple sodium hyaluronate injections and developed severe necrotizing fasciitis near the injection site. Conclusion. We recommend that clear guidelines for clean technique be put in place for use with sodium hyaluronate injections and consideration of full sterile technique in immunosuppressed patients.
\end{abstract}

\section{Introduction}

Osteoarthritis (OA), a degenerative joint disease, is a key cause of disability around the world and a large, ever-growing public health concern. Both obesity and the aging population are expected to increase the prevalence of OA $[1,2]$. Sixtyseven million Americans, about $25 \%$ of the adult population, are projected to have OA by 2030 [2]. OA is characterized by progressive cartilage damage and loss of the synovial fluid's lubricating and viscoelastic properties [3]. Intra-articular hyaluronic acid viscosupplementation was first approved by the Food and Drug Administration (FDA) in 1997 and is used as a conservative option for OA knee pain relief [13]. Synovial fluid and articular cartilage contain hyaluronan, a natural compound that reduces the coefficient of friction, thereby giving ease in joint movement [3]. An osteoarthritic knee has up to $50 \%$ less hyaluronan and the molecule itself is degraded, reducing its molecular weight. This causes increase in coefficient of friction and difficulty with joint movement [4]. Hyalgan (Fidia, S.p.A., Abano Terme, Italy) is a sodium hyaluronate intra-articular injectable medication, derived from rooster combs, having identical viscoelastic properties as human hyaluronic acid [5].

Viscosupplementation, with intra-articular sodium hyaluronate, is now a widely used method for treatment of knee OA. In general, the literature has shown an excellent safety profile for this treatment modality, with the most common adverse events being mild injection site pain and swelling $[1$, 4, 6-11]. In this report, we describe a case of a woman who had received a total of 30 sodium hyaluronate injections over the course of 5 years and developed severe necrotizing fasciitis near the injection site.

\section{Case Presentation}

Our patient is a 63-year-old female with osteoarthritis in the lumbar spine and bilateral knees. Knee X-rays showed bilateral mild osteoarthritic changes. MRI of left knee showed grade II-III patellar chondromalacia and mild osteoarthritic 
changes. Her left knee pain was uncontrolled with conservative measures including NSAIDs and narcotics. Steroid injections were provided once with no pain relief. Subsequently, over a period of five years, she received multiple courses of sodium hyaluronate injections to the left knee without complications, waiting at least six months between each series of five injections. The skin was thoroughly examined prior to each injection and was noted to be in a good condition, with no breaks, rashes, or bruises evident. She had great pain relief from the Hyalgan injections and repeatedly requested them. Clean technique was employed prior to each of these injections, including use of betadine, alcohol, and gloves.

Pertinent past medical history included treatment for invasive ductal left breast cancer with lumpectomy and radiation five years prior to this hospital presentation. She had been in remission until four months prior to hospitalization, when she was diagnosed with recurrent left breast ductal carcinoma. She then underwent mastectomy with axillary lymph node dissection and received one round of chemotherapy treatment, with Taxotere, Carboplatin, and Herceptin, 11 days prior to hospital admission. The surgery and chemotherapy proceeded without complications.

Five days after the last sodium hyaluronate injection to the left knee, she presented to the hospital with complaint of left leg pain that woke her from sleep. She initially noticed a small area of erythema in the left popliteal fossa. Over the next few hours, she developed rapidly progressive swelling, expansion of the erythema, and formation of multiple large bullae extending from the thigh to proximal leg. By the time she arrived at the hospital, the bullae and erythema had expanded to the gluteal fold and inguinal region. CT of left lower extremity showed free gas through the adductor musculature and posterior and superior to ischial tuberosity. Given the aggressive symptoms, the patient was emergently taken to operating room for extensive debridement and amputation at the lesser trochanter. She was then admitted to intensive care unit on broad spectrum antibiotics for septic shock secondary to necrotizing fasciitis of the left lower extremity, involving both posterior and anterior compartments. She deteriorated and required vasopressors, intubation and multiple debridements. Over the next 3 days, she suffered multiorgan failure and required hemodialysis. Given her wishes and poor prognosis, life support was withdrawn. She died 20 days after last chemo, 13 days after the most recent Hyalgan injection, and 7 days after the onset of necrotizing fasciitis.

\section{Discussion}

Necrotizing fasciitis is a rare, but potentially fatal, rapidly progressive soft tissue infection involving subcutaneous fat and fascia $[12,13]$. Early diagnosis, use of antibiotics, and debridement are essential [12, 13]. The causative bacteria could be aerobic, anaerobic, or mixed flora [12]. The most common pathogens are streptococci and S. aureus [12]. Risk factors include immunosuppression, diabetes, trauma, and operative infections [12]. There are case reports of necrotizing fasciitis occurring after intra-articular corticosteroid injections and diclofenac injections [14-19]. However, there are no previously described cases of necrotizing fasciitis following viscosupplementation. As mentioned earlier, sodium hyaluronate injections have proven to be quite safe and have a low incidence of serious side effects $[1,4,6-11]$. The overall incidence of side effects is approximately $1-3 \%$ per injection [20]. The most common side effects include injection site pain, GI complaints, local skin reaction, and pruritis; rare serious adverse outcomes are septic arthritis and gout $[6,20-$ 23].

Apart from the issue of adverse outcomes, the efficacy of viscosupplementation has recently been called into question [24-26]. In 2012, Rutjes et al. did a systematic review of 89 large trials, involving 12,667 patients, and showed that there was only a small, clinically irrelevant benefit in terms of pain, with no positive effect on function [24]. Jørgensen et al. did a multicenter, randomized, and double blinded study of 337 patients and found no improvement in pain or function compared to placebo. The American Association of Orthopedic Surgeons recommends neither for nor against the use of viscosupplemention for the nonarthroplasty treatment of OA of the knee based on their systematic review of the published studies [24, 25, 27].

Typically, patients who develop necrotizing fasciitis have a preexisting condition making them more susceptible to infection $[12,13]$. Our patient was recently treated for invasive ductal carcinoma of the left breast, with chemotherapy 11 days prior to hospitalization. She was likely immunosuppressed secondary to malignancy and recent use of chemotherapeutic agents. Necrotizing fasciitis most frequently occurs following local trauma which compromises skin integrity $[12,28]$. Our patient's rapidly spreading, fatal necrotizing fasciitis started near the site of her multiple injections. Sodium hyaluronate injections are contraindicated if infection or skin disease is present at the injection site, in order to reduce risk of septic arthritis [5]. However, there is no mention of avoiding viscosupplementation in immunosuppressed patients, such as diabetics or patients with underlying malignancy. Our patient was examined by physician prior to each injection and was noted to have no local skin condition near the injection site.

Though our patient had no skin compromise at the injection site, this possibly was the source of bacterial inoculation. The American College of Rheumatology guidelines state that sterile gloves should be worn for intra-articular steroid injections [29]. However, Charalambous et al., in their survey, noted that $53.4 \%$ of responders did not follow aseptic techniques prior to these injections [21]. It should further be noted that there are no proper guidelines regarding implementation of clean or aseptic technique with Hyalgan injections.

\section{Conclusion}

Despite the rarity of adverse events, intra-articular sodium hyaluronate injections can cause life-threatening infections. Furthermore, the long-term effectiveness of these injections is still a matter of debate [24, 25, 30, 31]. We recommend 
clear guidelines for clean technique be put in place for use with sodium hyaluronate injections. In immunosuppressed patients, it may be necessary to observe full sterile technique, given the increased likelihood of infection. Further studies should be done examining the incidence of adverse events following such injections in immunosuppressed patients. The practical implications of such studies could be crucial, as many patients receiving these injections may be on concomitant immunosuppressive agents such as disease modifying antirheumatic drugs (DMARDS) or chemotherapeutic agents.

\section{Conflict of Interests}

The authors declare that they have no competing interests.

\section{Authors' Contribution}

Shanti Virupannavar collected patient information and wrote the paper. Carla Guggenheim helped edit the paper and collect additional information.

\section{References}

[1] B. A. McArthur, C. J. Dy, P. D. Fabricant, and A. G. Valle, "Long term safety, efficacy, and patient acceptability of hyaluronic acid injection in patients with painful osteoarthritis of the knee," Patient Preference and Adherence, vol. 2012, article 6, pp. 905910, 2012.

[2] J. M. Hootman and C. G. Helmick, "Projections of US prevalence of arthritis and associated activity limitations," Arthritis \& Rheumatism, vol. 54, no. 1, pp. 226-229, 2006.

[3] T.-L. Huang, C.-C. Chang, C.-H. Lee, S.-C. Chen, C.-H. Lai, and C.-L. Tsai, "Intra-articular injections of sodium hyaluronate (Hyalgan) in osteoarthritis of the knee. a randomized, controlled, double-blind, multicenter trial in the Asian population," BMC Musculoskeletal Disorders, vol. 12, article 221, 2011.

[4] T. E. Clegg, D. Caborn, and C. Mauffrey, "Viscosupplementation with hyaluronic acid in the treatment for cartilage lesions: a review of current evidence and future directions," European Journal of Orthopaedic Surgery \& Traumatology, vol. 23, no. 2, pp. 119-124, 2013.

[5] "Hyalgan [package insert]," Fidia Pharma, Parsippany, NJ, USA, 2011.

[6] J. F. R. Hammesfahr, A. B. Knopf, and T. Stitik, "Safety of intraarticular hyaluronates for pain associated with osteoarthritis of the knee," The American Journal of Orthopedics, vol. 32, no. 6, pp. 277-283, 2003.

[7] D. Neustadt, J. Caldwell, M. Bell, J. Wade, and J. Gimbel, "Clinical effects of intraarticular injection of high molecular weight hyaluronan (Orthovisc) in osteoarthritis of the knee: a randomized, controlled, multicenter trial," The Journal of Rheumatology, vol. 32, no. 10, pp. 1928-1936, 2005.

[8] M. M. Cohen, R. D. Altman, R. Hollstrom, C. Hollstrom, C. Sun, and B. Gipson, "Safety and efficacy of intra-articular sodium hyaluronate (Hyalgan) in a randomized, double-blind study for osteoarthritis of the ankle," Foot \& Ankle International, vol. 29, no. 7, pp. 657-663, 2008.

[9] D. H. Neustadt, "Long-term efficacy and safety of intra-articular sodium hyaluronate (Hyalgan) in patients with osteoarthritis of the knee," Clinical and Experimental Rheumatology, vol. 21, no. 3, pp. 307-311, 2003.

[10] P. Jüni, S. Reichenbach, S. Trelle et al., "Efficacy and safety of intraarticular hylan or hyaluronic acids for osteoarthritis of the knee: a randomized controlled trial," Arthritis \& Rheumatism, vol. 56, no. 11, pp. 3610-3619, 2007.

[11] C. Peterson and J. Hodler, "Adverse events from diagnostic and therapeutic joint injections: a literature review," Skeletal Radiology, vol. 40, no. 1, pp. 5-12, 2011.

[12] D. K. Das, M. G. Baker, and K. Venugopal, "Risk factors, microbiological findings and outcomes of necrotizing fasciitis in New Zealand: a retrospective chart review," BMC Infectious Diseases, vol. 12, article 348, 2012.

[13] B. Sarani, M. Strong, J. Pascual, and C. W. Schwab, "Necrotizing fasciitis: current concepts and review of the literature," Journal of the American College of Surgeons, vol. 208, no. 2, pp. 279-288, 2009.

[14] F. Fanfarillo, F. Pace, R. Maida, D. Pignata, and G. Cerqua, "Necrotizing fasciitis following intra-articular steroid injection: case report and review of the literature," Geriatrics \& Gerontology International, vol. 12, no. 2, pp. 353-355, 2012.

[15] A. Yam, L.-C. Teoh, and F.-C. Yong, "Necrotising fasciitis after corticosteroid injection for trigger finger: a severe complication from a "safe" procedure," The Journal of Hand Surgery, vol. 34, no. 5, pp. 689-690, 2009.

[16] F. Unglaub, T. Guehring, P. C. Fuchs, A. Perez-Bouza, A. Groger, and N. Pallua, "Necrotizing fasciitis following therapeutic injection in a shoulder joint," Orthopade, vol. 34, no. 3, pp. 250-252, 2005.

[17] R. Birkinshaw, J. O’Donnell, and I. Sammy, "Necrotising fasciitis as a complication of steroid injection," Journal of Accident \& Emergency Medicine, vol. 14, no. 1, pp. 52-54, 1997.

[18] G. Okan, S. Yaylaci, U. Ince, and S. Zorer, "Necrotizing fasciitis following intramuscular diclofenac injection," Journal of the European Academy of Dermatology and Venereology, vol. 22, no. 12, pp. 1521-1522, 2008.

[19] G. Verfaillie, S. Knape, and L. Corne, "A case of fatal necrotizing fasciitis after intramuscular administration of diclofenac," European Journal of Emergency Medicine, vol. 9, no. 3, pp. 270-273, 2002.

[20] S. Shemesh, S. Heller, M. Salai, and S. Velkes, "Septic arthritis of the knee following intraarticular injections in elderly patients: report of six patients," Israel Medical Association Journal, vol. 13, no. 12, pp. 757-760, 2011.

[21] C. P. Charalambous, M. Tryfonidis, S. Sadiq, P. Hirst, and A. Paul, "Septic arthritis following intra-articular steroid injection of the knee-a survey of current practice regarding antiseptic technique used during intra-articular steroid injection of the knee," Clinical Rheumatology, vol. 22, no. 6, pp. 386-390, 2003.

[22] C. Albert, O. Brocq, D. Gerard, C. Roux, and L. Euller-Ziegler, "Septic knee arthritis after intra-articular hyaluronate injection: two case reports," Joint Bone Spine, vol. 73, no. 2, pp. 205-207, 2006.

[23] E. A. Yacyshyn and E. L. Matteson, "Gout after intraarticular injection of hylan GF-20 (Synvisc)," The Journal of Rheumatology, vol. 26, no. 12, article 2717, 1999.

[24] A. W. Rutjes, P. Jüni, B. R. da Casta, S. Trelle, E. Nüesch, and S. Reichenbach, "Viscosupplementation for osteoarthritis of the knee: a systemic review and meta-analysis," Annals of Internal Medicine, vol. 157, no. 3, pp. 180-191, 2012. 
[25] J. Richmond, D. Hunter, J. Irrgang et al., "Treatment of osteoarthritis of the knee (nonarthoplasty)," Journal of the American Academy of Orthopaedic Surgeons, vol. 17, no. 9, pp. 591-600, 2009.

[26] K. Taviloglu, N. Cabioglu, A. Cagatay et al., "Idiopathic necrotizing fasciitis: risk factors and strategies for management," American Surgeon, vol. 71, no. 4, pp. 315-320, 2005.

[27] J. Richmond, D. Hunter, J. Irrgang et al., "American academy of orthopaedic surgeons clinical practice guideline on the treatment of osteoarthritis (OA) of the knee," The Journal of Bone \& Joint Surgery, vol. 92, no. 4, pp. 990-993, 2010.

[28] A. J. Headley, "Necrotizing soft tissue infections: a primary care review," American Family Physician, vol. 68, no. 2, pp. 323-328, 2003.

[29] M. C. Hochberg, R. D. Altman, K. T. April et al., "American College of Rheumatology 2012 recommendations for the use of nonpharmacologic and pharmacologic therapies in osteoarthritis of the hand, hip, and knee," Arthritis Care \& Research, vol. 64, no. 4, pp. 465-474, 2012.

[30] A. Jørgensen, K. Stengaard-Pedersen, O. Simonsen et al., "Intra-articular hyaluronan is without clinical effect in knee osteoarthritis: a multicentre, randomised, placebo-controlled, double-blind study of 337 patients followed for 1 year," Annals of the Rheumatic Diseases, vol. 69, no. 6, pp. 1097-1102, 2010.

[31] Eisenberg Center at Oregon Health and Sciences University, "Three treatments for osteoarthritis of the knee: evidence shows lack of benefit," Agency for Healthcare Research and Quality (US), 2009 . 


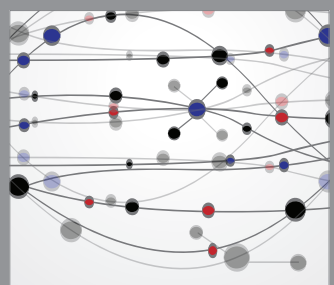

The Scientific World Journal
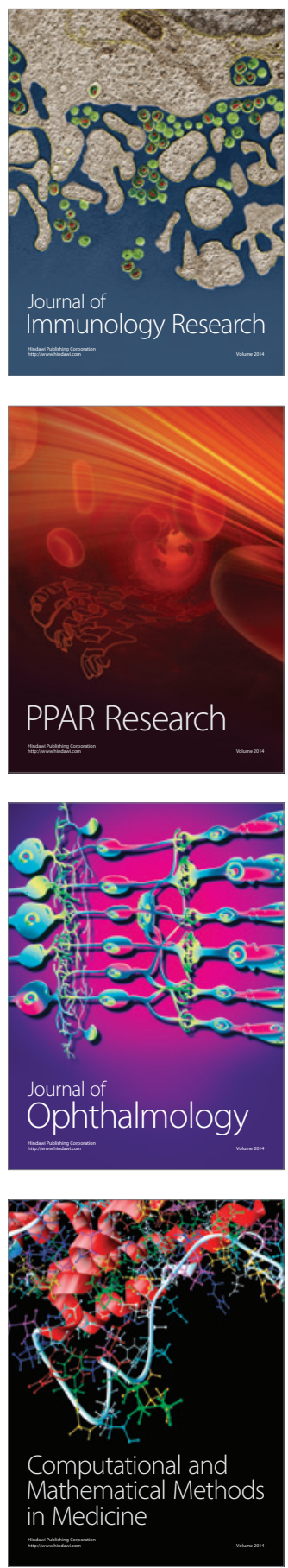

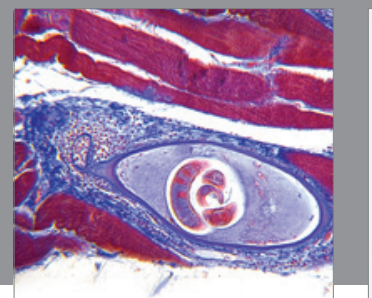

Gastroenterology

Research and Practice
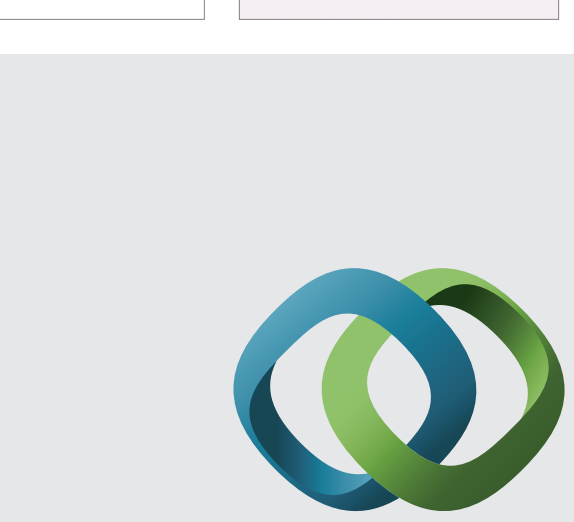

\section{Hindawi}

Submit your manuscripts at

http://www.hindawi.com
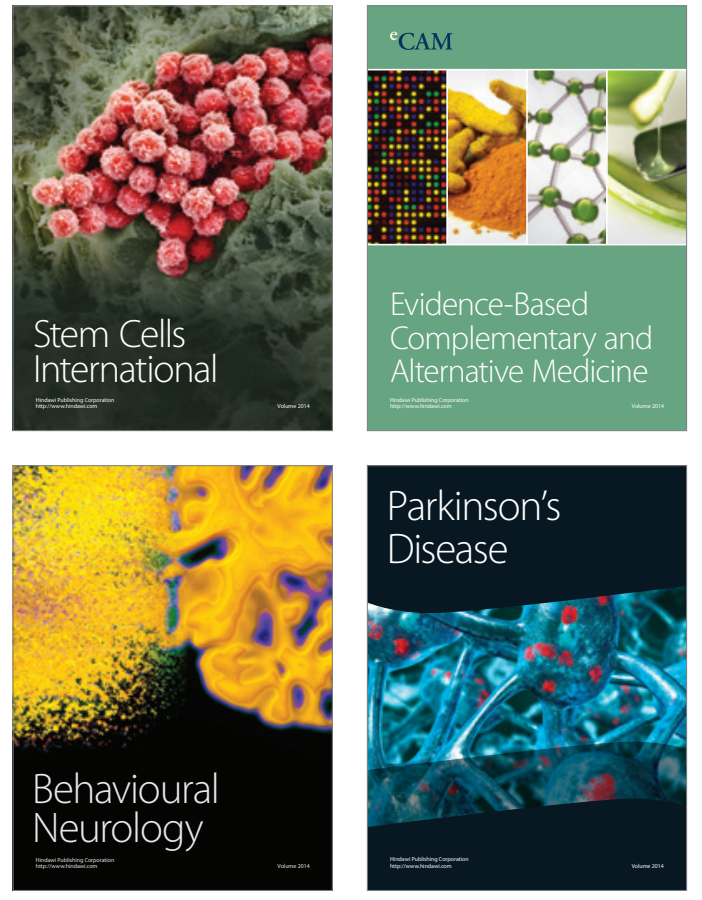
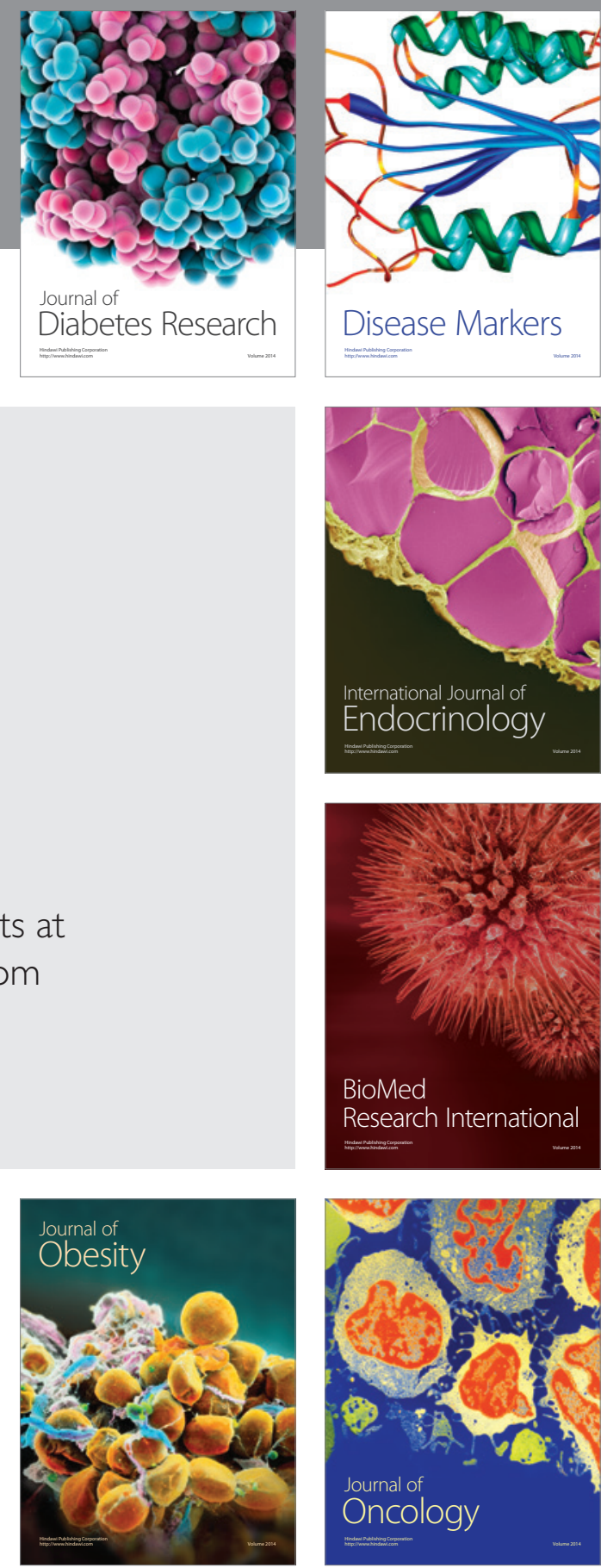

Disease Markers
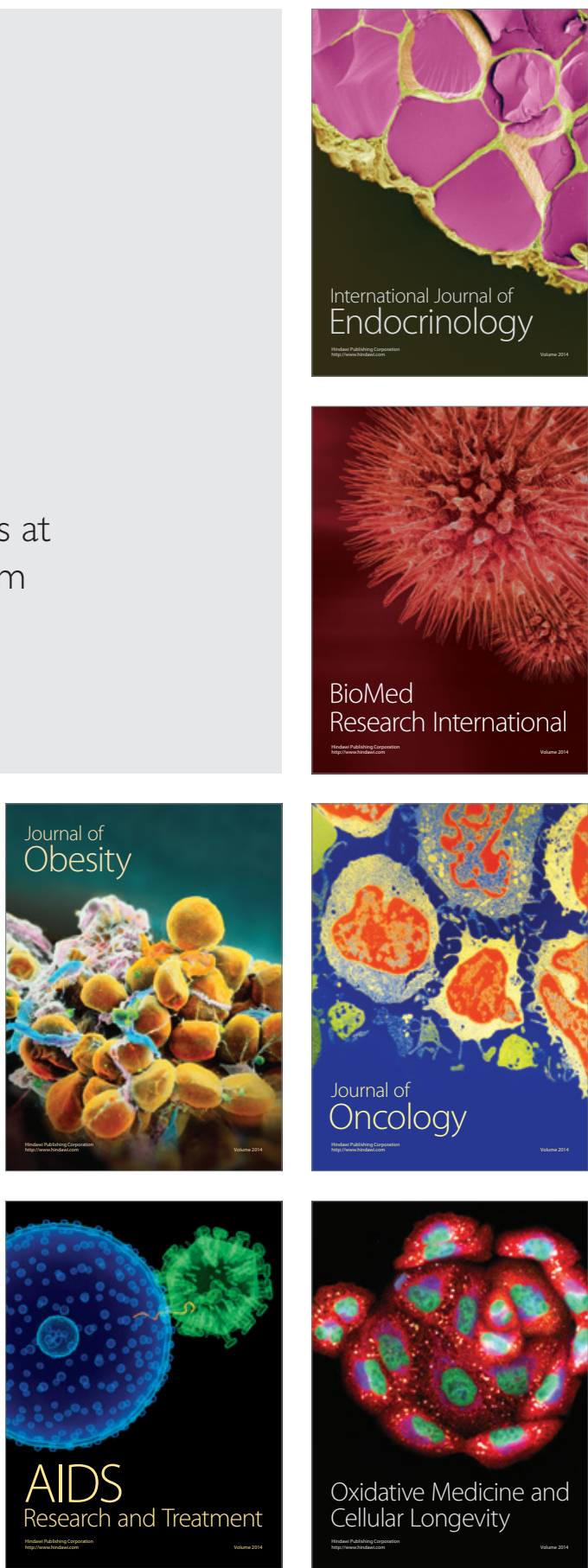